\section{In-Vitro Model of Scardovia wiggsiae Biofilm Formation and Effect of Nicotine}

\author{
Abdulrahman A. Balhaddad ${ }^{1}{ }^{\oplus}$, Hadeel M. Ayoub $2,3 \oplus$, Richard L. Gregory ${ }^{3} \bullet$
}

Recently, Scardovia wiggsiae has been reported to be strongly associated with caries formation. This study aimed to establish an in vitro model of S. wiggsiae biofilm and to investigate the effect of nicotine on S. wiggsiae colony-forming units (CFUs) growth. S. wiggsiae biofilm was grown overnight using brain-heart infusion (BHI) broth supplemented with $5 \mathrm{~g}$ of yeast extract/L (BHI-YE). The overnight culture was used as an inoculum to grow S. wiggsiae biofilm on standardized enamel and dentin samples. Samples were incubated with different nicotine concentrations $(0,0.5,1,2,4,8,16$ and $32 \mathrm{mg} / \mathrm{mL})$ for 3 days. The dissociated biofilms were diluted, spiral plated on blood agar plates, and incubated for $24 \mathrm{~h}$. CFUs/mL were quantified using an automated colony counter. A twoway ANOVA was used to compare the effect of different nicotine concentrations on $S$. wiggsiae CFUs. This study demonstrated that $S$. wiggsiae biofilm could be initiated and formed in vitro. Increased CFUs was observed through $0.5-4 \mathrm{mg} / \mathrm{mL}$ and $0.5-8 \mathrm{mg} / \mathrm{mL}$ of nicotine using enamel and dentin substrates, respectively. 16 and $32 \mathrm{mg} / \mathrm{mL}$ of nicotine were determined as the minimum inhibitory concentration (MIC) and the minimum bactericidal concentration (MBC), respectively. S. wiggsiae formed greater biofilm on enamel than dentin specimens in response to the nicotine stimulus. This study demonstrated the negative effect of smoking on increasing S. wiggsiae biofilm. Establishing S. wiggsiae biofilm in vitro may allow researchers in the future to have a better understanding of caries pathogenesis and bacterial interaction.
'Imam Abdulrahman Bin Faisal University, Department of Restorative Dental Sciences, College of Dentistry, Dammam, Saudi Arabia ${ }^{2}$ King Saud University, Dental Health Department, College of Applied Medical Sciences, Riyadh, Saudi Arabia ${ }^{3}$ Indiana University, School of Dentistry, Department of Biomedical and Applied Sciences

Correspondence: Abdulrahman A. Balhaddad, Imam Abdulrahman Bin Faisal University, Dammam, Saudi Arabia, 34212. e-mail: aabalhaddad@umaryland.edu

Key Words: biofilm, dental caries, nicotine, scardovia wiggsiae.

\section{Introduction}

Streptococcus mutans and Lactobacillus are known as the two most common responsible microorganisms to cause caries $(1,2)$. In 2011, Tanner et al. discovered a new microbe associated with dental caries, Scardovia wiggsiae. They investigated the microbial composition of dental plaque associated with early childhood caries in 42 children and compared them with 40 caries-free children. It was found that S. wiggsiae, S. wiggsiae, Veillonella parvula, Streptococcus cristatus, and Actinomyces gerensceriae are the major species that were seen in children with carious lesions. More interestingly, S. wiggsiae was observed in carious lesions even without the presence of S. wiggsiae (3). S. wiggsiae was also found in patients aged between 1019 who were under orthodontic treatment and had white spot lesions (4). Another report indicated that S. wiggsiae prevalence is higher with the presence of carious lesions (5).

The interrelationship between smoking and dental caries has been stated in the literature (6). Also, the use of tobacco was linked to the presence of root carious lesions and may increase the risk of developing new lesions (7). A recent report has shown that $S$. wiggsiae isolated from smokers grew more biofilms compared to their non-smokers counterparts (8), which may increase the risk of having caries among smokers. The risk of having dental caries is not only associated with the first-hand smoke, but also with the second-hand smoke (negative tobacco exposure). A cohort study found that the second-hand smoke could be associated with high risk of caries in deciduous teeth $(9,10)$. Children living in regularly smoking homes were found to have a higher prevalence of primary teeth caries (44\%) compared to those living in non-regularly/non-smoking homes (25\%) (11). Moreover, individuals affected by secondhand smoke were found to have more $S$. wiggsiae and lactobacilli colonization (12). This data supports the need of limiting second-hand smoke exposure, but it should be interrupted carefully as the causality was not proven yet.

Several in-vitro studies also demonstrated the negative effects of nicotine. Nicotine was found to increase the cariogenicity of $S$. wiggsiae by promoting glucosyltransferase activity, glucan binding proteins expression, biofilm formation, and the amount of extracellular polysaccharide (EPS) $(13,14)$. Despite the fact that many studies have demonstrated the association between smoking and an increased incidence of dental caries (6), more investigations are needed to emphasize the results of these studies. Nicotine was found also to increase the growth of several other oral species such as Prevotella gingivalis, Lactobacillus casei, Actinomyces viscosus, Rothia dentocariosa, Enterococcus faecalis and Candida albicans. Therefore, smokers are at a higher risk to develop periodontal diseases, dental caries, and denture 
stomatitis (15).

The effect of smoking on caries-related pathogens and associated virulence factors is a hot-spot research area in dentistry. The effect of nicotine, the main addictive material in smoking cigarette, on S. wiggsiae biofilm was investigated before, but no data has been reported in relation to $S$. wiggsiae. Therefore, the aim of this study was to investigate the colony-forming units (CFUs) growth of $S$. wiggsiae responding to different nicotine concentrations in vitro using enamel and dentin specimens.

\section{Material and Methods}

\section{Sample Preparation}

Based on Institutional Review Board (IRB) approval (\#NS0911-07), intact human teeth were collected, stored in $0.1 \%$ thymol solution at $4{ }^{\circ} \mathrm{C}$, and used within three months. Fifty standardized radicular dentin samples $(2 \times 2$ $x 2 \mathrm{~mm}^{3}$ ) were obtained from roots, and 50 enamel samples $\left(2 \times 2 \times 2 \mathrm{~mm}^{3}\right)$ were obtained from the buccal surface using a slow diamond saw (IsoMet; Buehler, Lake Bluff, IL, USA) under continuous distilled water irrigation. The samples were polished then sonicated in deionized water for three minutes, washed with sterile water, sterilized using a high-pressure steam autoclave (16), and maintained in $100 \%$ humidity at $4{ }^{\circ} \mathrm{C}$ until used.

\section{Bacterial Strain and Media}

S. wiggsiae (kindly provided by Dr. Ann Tanner, Forsyth Dental Center, Boston, MA, USA; strain designation F0424) was grown initially on anaerobic blood agar plates (CDC; BioMerieux, Durham, NC, USA). Colonies of $S$. wiggsiae were suspended in brain-heart infusion (BHI) broth supplemented with $5 \mathrm{~g}$ of yeast extract/L (BHI-YE) and incubated for 24 h at $37^{\circ} \mathrm{C}$ with $5 \% \mathrm{CO}_{2}$.

\section{Biofilm Growth}

Sterile enamel and dentin samples were placed individually in separate wells of a sterile 24 well plate (FisherBrand, Fisher Scientific International Inc., Hampton, VA, USA). Then, $50 \mu \mathrm{L}$ of an overnight $S$. wiggsiae culture (approximately 106 colony-forming units [CFUs] $/ \mathrm{mL}$ ) dispersed in $2 \mathrm{~mL}$ of fresh BHI-YE growth media was added to each sample (Fig. 1A). The wells were divided into sixteen groups (four wells for each group) according to the amount of nicotine concentration; $0,0.5,1,2,4,8,16$ and $32 \mathrm{mg} /$ $\mathrm{mL}$ nicotine $(13,14)$ (Sigma-Aldrich Chemical Co., St. Louis, MO, USA), and according to the type of tissue (enamel or dentin). These nicotine concentrations were selected based on our previous experience with nicotine-induced biofilms $(13,14)$. The concentrations represent a constant nicotine load that could be found in saliva or dental plaque. Samples were incubated anaerobically for 3 days at $37^{\circ} \mathrm{C}$.
To confirm the purity of the formed S. wiggsiae biofilm, four sterilized samples, two dentin and two enamel, were independently immersed in $2 \mathrm{~mL}$ of bacterial-free BHI-YE growth media and incubated anaerobically for three days as previously described. After the incubation, the biofilm disruption assay described below was used to confirm the absence of any bacterial contamination in these noninfected samples.

\section{Biofilm Disruption Assay}

After three days of incubation, the BHI-YE fluid above the enamel or dentin specimens was aspirated and removed. Each specimen was gently washed with sterile saline to remove unattached bacteria and immersed in a sterile plastic test tube containing $1 \mathrm{~mL}$ of sterile saline, vortexed for $10 \mathrm{~s}$, sonicated for $10 \mathrm{~s}$, and then vortexed again for $10 \mathrm{~s}$ to detach biofilm cells (Fig. 1B). A pilot study was conducted before this experiment to confirm that the biofilm detachment technique did not cause any bacterial lysis or false-negative results. The dissociated biofilms were diluted, spiral plated on blood agar plates (Fig. 1C), and incubated for $24 \mathrm{~h}$ in $5 \% \mathrm{CO}_{2}$ at $37^{\circ} \mathrm{C}$. CFUs $/ \mathrm{mL}$ were quantified using an automated colony counter (Synbiosis, Inc, Frederick, MD, USA) (Fig. 1D).

\section{Statistical Analysis}

Each group in each individual experiment consisted of 4 wells, and the experiment was performed in triplicate to gain statistical confidence ( $n=12$ per group). A Twoway ANOVA was used to compare the effect of different nicotine concentrations on $S$. wiggsiae biofilm formulation (as measured by $\mathrm{CFU} / \mathrm{mL}$ ) on both human enamel and dentin. Pair-wise comparisons were achieved using Fisher's Protected Least Significant Differences method to control the overall significance level at $\alpha=.05$. The primary focus of the study hypotheses were the comparisons involving infected enamel and dentin samples exposed to different concentrations of nicotine. The distribution of the measurements was investigated and data transformation was not necessary to satisfy the ANOVA assumptions. Based on prior studies, the within-group standard deviation of the measurements for biofilm formation was estimated to be 0.15 . With 4 samples in each of 3 replicates of the study, the study power was estimated to be $80 \%$ power to detect a difference of 0.2 between substrates for each nicotine concentration, assuming 2-sided tests were conducted at 0.05 level of significance $(p<0.05)$. Statistical analyses were performed using Sigma Plot (SYSTAT, Chicago, IL, USA).

\section{Results}

Overall, there was a significant effect for nicotine presence, tissue type (enamel and dentin), and their 
interaction to form S. wiggsiae biofilm $(p=<0.05)$. The results of this experiment demonstrated that nicotine was able to increase the amount of $S$. wiggsiae biofilm formation. In enamel specimens (Fig. 2A), S. wiggsiae biofilm formation increased slightly with $0.5 \mathrm{mg} / \mathrm{mL}$ of nicotine and significantly with 1,2 and $4 \mathrm{mg} / \mathrm{mL}$ of nicotine $(p=<0.05)$ as the amount of biofilm was enhanced by around 2-fold. Then, the amount of biofilm was reduced with 8 and 16 $\mathrm{mg} / \mathrm{mL}$ of nicotine but the amount of CFUs was comparable to the control. No growth was observed with $32 \mathrm{mg} / \mathrm{mL}$ of nicotine. In dentin specimens (Fig. 2B), nicotine increased the amount of biofilm when the nicotine concentration

A

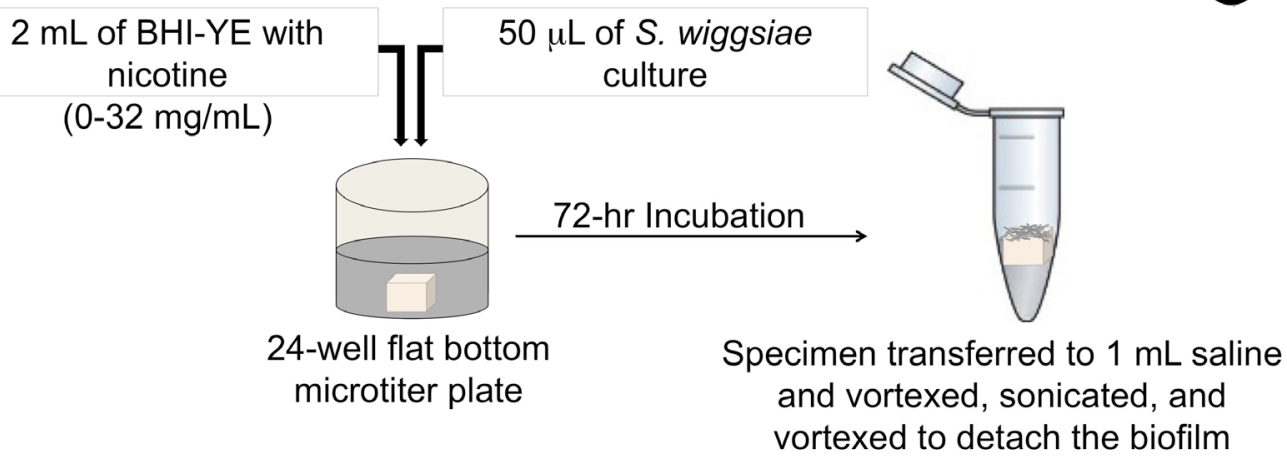

C

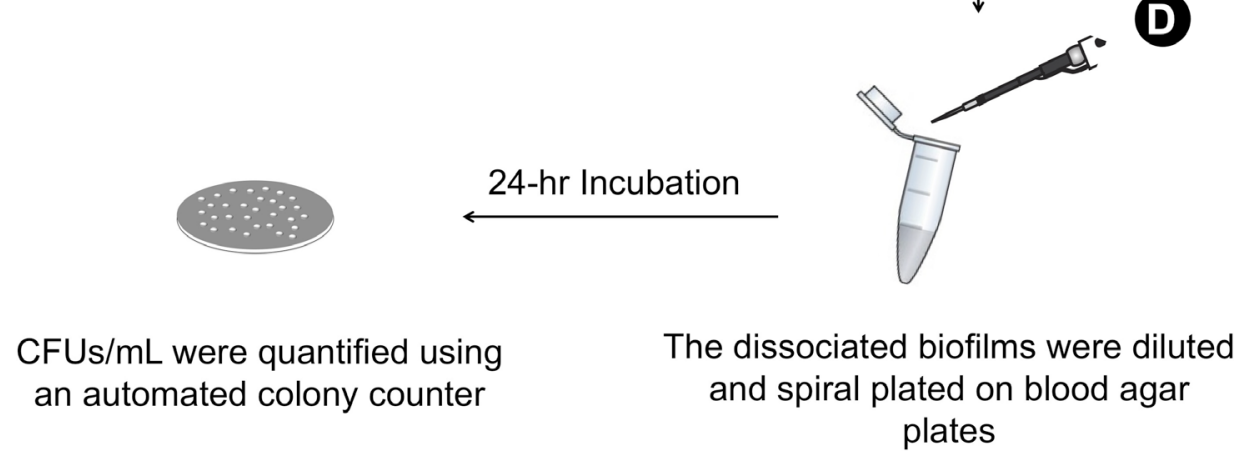

Figure 1. Schematic diagram of initiation of the biofilm using the 24-well microtiter plate. A: Enamel/dentin specimens were placed in a 24-well plate with the inoculum B: Each specimen was transferred to an Eppendorf tube containing $1 \mathrm{~mL}$ sterile saline. C: The detached biofilm was plated and incubated for 24 h. D: S. wiggsiae CFUs were counted
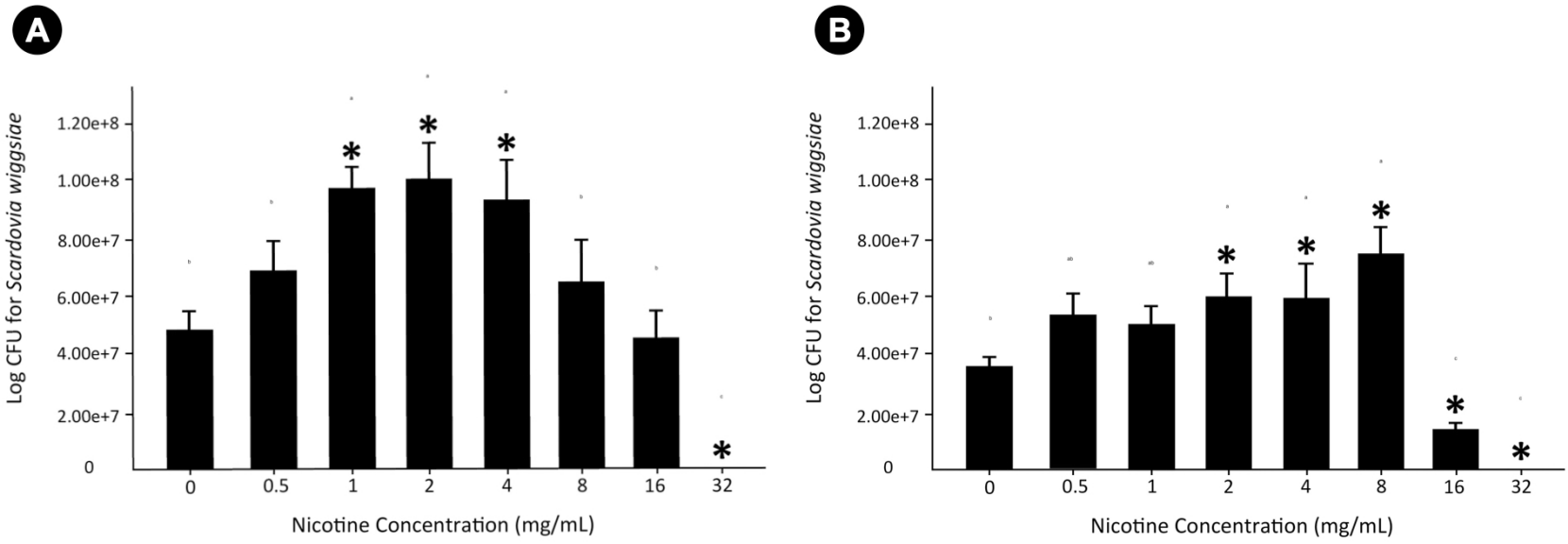

Figure 2. Colony-forming unit (CFU) counts of S. wiggsiae biofilm subjected to different nicotine concentrations using (A) enamel, and (B) dentin specimens as a growing substrate surface $\left(m_{e a n} \pm s d ; n=12\right)$. Asterisks indicate significant differences $(p<0.05)$ compared to control samples without nicotine. Values indicated by different letters are statistically different from each other $(\mathrm{p}<0.05)$ 
was between $0.5-8 \mathrm{mg} / \mathrm{mL}$ with a significant amount of biofilm with 2,4 , and $8 \mathrm{mg} / \mathrm{mL}$ of nicotine $(p=<0.05) .8 \mathrm{mg} /$ $\mathrm{mL}$ of nicotine was associated with the greatest amount biofilm as S. wiggsiae biofilm increased by around 2-fold. Then, reduced CFUs were observed with 16 and $32 \mathrm{mg} / \mathrm{mL}$ of nicotine. The minimum inhibitory concentration (MIC) was determine as the lowest concentration of an agent that inhibits the visible growth of a microorganism, and the minimum bactericidal concentration (MBC) as the lowest concentration of an agent that kills the microorganism. In both enamel and dentin, 16 and $32 \mathrm{mg} / \mathrm{mL}$ of nicotine were determined as the MIC and the MBC, respectively. Enamel specimens demonstrated significantly higher amounts of biofilm formation compared to dentin when the nicotine concentration was 1, 2, 4 or $16 \mathrm{mg} / \mathrm{mL}$ of nicotine (Fig. 3).

\section{Discussion}

In this study, the hypotheses were proven that specific nicotine concentrations were associated with higher $S$. wiggsiae biofilm in both enamel and dentin. This study was the first to establish $S$. wiggsiae biofilm formation in vitro, and also the first that investigated the effect of nicotine on S. wiggsiae. Establishing S. wiggsiae biofilm in vitro may allow researchers in the future to have a better understanding of dental caries pathogenesis and bacterial interaction. Because of the increased caries incidence in smokers and the fact that $S$. wiggsiae is a relatively newly discovered cariogenic microbe, it is important to learn what levels of nicotine may affect $S$. wiggsiae growth and biofilm formation. The results of this study demonstrated that $0.5-4 \mathrm{mg} / \mathrm{mL}$ of nicotine using enamel substrates and $0.5-8 \mathrm{mg} / \mathrm{mL}$ of nicotine using dentin substrates increased the amount of $S$. wiggsiae biofilm. In addition, 16 and 32 $\mathrm{mg} / \mathrm{mL}$ of nicotine were recorded as MIC and MBC.

These findings are similar to other reported oral

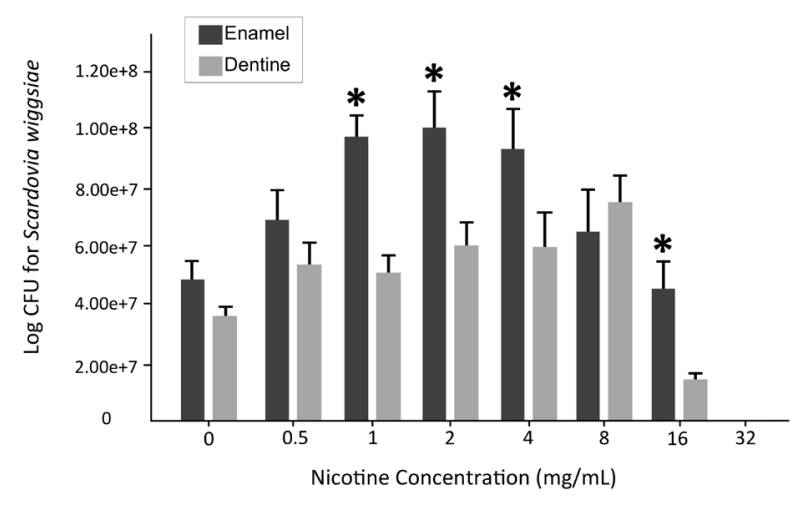

Figure 3. S. wiggsiae biofilm formation on dentin versus enamel surfaces. Asterisks indicate significant differences $(p<0.05)$ comparing the amount of biofilm formation between dentin and enamel surfaces at a specific concentration of nicotine pathogens exposed to nicotine. The most important oral pathogens such as $S$. wiggsiae, P. gingivalis, L. casei, $A$. viscosus, $R$. dentocariosa, E. faecalis and $C$. albicans were associated with enhanced biofilm formation with 1-8 mg/ $\mathrm{mL}$ of nicotine in vitro $(14,15,17)$. Based on that, it can be said that the findings of this study support the hypothesis relating tobacco smoking to different oral health issues by promoting the growth and activities of associated pathogens. However, Actinomyces naes/undii is the only reported microorganism with decreased biofilm growth over the exposure to different nicotine concentrations (17).

The clinical importance of our results can be related to the amount of nicotine in the saliva of smokers. Feyerabend et al. (18) found that the nicotine level in the saliva of light/medium smokers was between $0-1.33 \mathrm{mg} / \mathrm{mL}$. As for heavy smokers, the level of nicotine was measured between $0-2.27 \mathrm{mg} / \mathrm{mL}$. For those individuals who were not smokers but were exposed to second or tertiary-hand smoke, the level of nicotine in their saliva was lower at $0-0.31 \mathrm{mg} /$ $\mathrm{mL}$ (18). Another study indicated that the nicotine level was between $0.07-1.56 \mathrm{mg} / \mathrm{mL}$ for individuals with ten years of smoking history (19). It could be inferred from this study that smokers and individuals who are affected by first-hand smoke may have a higher prevalence and higher metabolic activity of $S$. wiggsiae. Supposing the average level of nicotine in smokers' saliva ranges between 1-2 $\mathrm{mg} / \mathrm{mL}$, S. wiggsiae biofilms over enamel and dentin could be increased, making the tooth at higher risk of demineralization. The range of nicotine, reported in the literature, among second and tertiary-hand smoke individuals is less than the nicotine concentrations where S. wiggsiae biofilm started to increase. However, it is very important when discussing this point to be aware that this study reported a short-time exposure of nicotine for only three days. Having a long-time exposure could be associated with biofilm growth even with a very small concentration. This explanation could be supported by the available evidence that demonstrated an increased prevalence of caries in individuals affected by second-hand smoke (9-11). Besides, it is worth saying that nicotine concentration in dental plaque is also important in this process, which could be similar or different than what is found in saliva. Up to our knowledge, no study has yet investigated the load of nicotine inside the dental plaque. Therefore, it could be useful to include more concentrations to not only observe the growth of such microorganism, but also to determine the MIC and the MBC of the nicotine.

Before conducting this study, S. wiggsiae biofilm formation was attempted using a 96 sterile well plate (FisherBrand, Fischer Scientific) following methods similar to other reports $(13,14)$. The biofilm was fixed with formaldehyde, stained with crystal violet and the 
absorbance measured to determine biofilm formation using a spectrophotometer. A loose attachment of the bacterium was observed in the bottom of each well, and the amount of biofilm formation was very low. This experiment was repeated many times using different strategies in order to increase the amount of firmly attached biofilm. These strategies included the use of different media such as BHI, BHI-YE and TSBS (Tryptic Soy Broth supplemented with $1 \%$ sucrose), using potential binding proteins including albumin and mucin, and increasing the time of incubation to three days in order to enhance biofilm attachment. But the results were the same with loosely attached biofilm observed in every trial. To overcome this problem, enamel and dentin samples were prepared to investigate the ability of S. wiggsiae to form a biofilm in vitro. A significant amount of firmly attached biofilm was observed without nicotine on both enamel and dentin.

Dentin has fewer minerals and is highly subject to collagen degradation compared to enamel. Therefore, dentin is more susceptible to demineralization and bacterial invasion. This study revealed the ability of $S$. wiggsiae to form higher amount of biofilm on enamel compared to dentin. The reason for such a finding is not clear. There is no previous study explaining the adhesion mechanism of this microorganism. This is why we think that establishing an in vitro model for this bacteria is very important for future reports to investigate the pathogenesis and characteristics of S. wiggsiae. In this study, biofilms growing on enamel and dentin are almost similar when the nicotine concentrations were 0 and $0.5 \mathrm{mg} / \mathrm{mL}$. As a result, it could be suggested that $S$. wiggsiae may not express enough amounts of collagen-binding proteins. However, as the nicotine concentration increased, the difference in biofilm growth became more noticeable between the two substrates. These results could suggest that nicotine upregulates $S$. wiggsiae receptors specific for enamel preferentially over dentin. These receptors may be specific for hydroxyapatite. Alternatively, such an observation could suggest the onset of a specific interaction between nicotine and released enamel cellular components, which therefore promoted the growth of S. wiggsiae biofilm. Another explanation could be the opposite; a specific interaction between nicotine and released dentin cellular components could negatively affect the growth of S. wiggsiae biofilm.

Limitations of the present study include that this was an in vitro study; therefore, clinical studies are needed to confirm these results. Comparing the oral isolates between individuals affected by first, second, or tertiary-hand smoke and individuals who are not affected may provide a better idea about the relation between smoking and S. wiggsiae. Also, this study did not investigate how nicotine increased the biofilm formation of $S$. wiggsiae. Further studies may examine the effect of nicotine on the cariogenic virulence of $S$. wiggsiae. Future studies may investigate why nicotinetreated S. wiggsiae grows better on enamel than dentin. As this study was conducted using a single species biofilm, future experiments may investigate $S$. wiggsiae interaction with other species such as $S$. wiggsiae and other cariesrelated pathogens.

Establishing S. wiggsiae biofilm in vitro may allow researchers in the future to have a better understanding of dental caries pathogenesis and bacterial interaction. In addition, this study emphasized the negative effect of smoking by increasing biofilm formation of nicotinetreated $S$. wiggsiae on enamel and dentin substrates.

\section{Resumo}

Recentemente, foi relatado que Scardovia wiggsiae está fortemente associado à formação de cáries. Este estudo teve como objetivo estabelecer um modelo in vitro de biofilme de $S$. wiggsiae e investigar o efeito da nicotina no crescimento de unidades formadoras de colônias (UFC) de $S$. wiggsiae. 0 biofilme de $S$. wiggsiae foi cultivado durante a noite usando caldo de infusão de cérebro-coração (BHI) suplementado com $5 \mathrm{~g}$ de extrato de levedura / L (BHI-YE). A cultura noturna foi usada como um inóculo para cultivar biofilme de $S$. wiggsiae em amostras padronizadas de esmalte e dentina. As amostras foram incubadas com diferentes concentrações de nicotina $(0,0,5,1,2,4,8,16$ e $32 \mathrm{mg} / \mathrm{mL})$ por 3 dias. Os biofilmes dissociados foram diluídos, semeados em espiral em placas de ágar sangue e incubados por $24 \mathrm{~h}$. UFC/mL foram quantificados usando um contador de colônias automatizado. Uma ANOVA de duas vias foi usada para comparar o efeito de diferentes concentrações de nicotina em UFCs de S. wiggsiae. Este estudo demonstrou que o biofilme de $S$. wiggsiae pode ser iniciado e formado in vitro. UFCs aumentadas foram observadas com 0,5-4 mg/mL e 0,5-8 mg/ $\mathrm{mL}$ de nicotina usando substratos de esmalte e dentina, respectivamente. $\mathrm{A}$ concentração inibitória mínima (CIM) e a concentração bactericida mínima (CBM) de nicotina foram determinadas, respectivamente, como 16 e 32 $\mathrm{mg} / \mathrm{mL}$. S. wiggsiae formou maior biofilme no esmalte do que espécimes de dentina em resposta ao estímulo de nicotina. Este estudo demonstrou o efeito negativo do tabagismo no aumento do biofilme de $S$. wiggsiae. 0 estabelecimento do biofilme de $S$. wiggsiae in vitro pode permitir que os pesquisadores no futuro tenham uma melhor compreensão da patogênese da cárie e da interação bacteriana.

\section{References}

1. Balhaddad AA, Kansara AA, Hidan D, Weir MD, Xu HHK, Melo MAS. Toward dental caries: Exploring nanoparticle-based platforms and calcium phosphate compounds for dental restorative materials. Bioact Mater 2019;4:43-55.

2. Peterson SN, Snesrud E, Liu J, Ong AC, Kilian M, Schork NJ, et al. The dental plaque microbiome in health and disease. PloS One 2013;8:e58487.

3. Tanner ACR, Mathney JMJ, Kent RL, Chalmers NI, Hughes CV, Loo CY, et al. Cultivable anaerobic microbiota of severe early childhood caries. J Clin Microbiol 2011;49:1464-1474.

4. Tanner ACR, Sonis AL, Lif Holgerson P, Starr JR, Nunez Y, Kressirer CA, et al. White-spot lesions and gingivitis microbiotas in orthodontic patients. J Dent Res 2012;91:853-858.

5. Henne K, Rheinberg A, Melzer-Krick B, Conrads G. Aciduric microbial taxa including Scardovia wiggsiaeand Bifidobacterium spp. in caries and caries free subjects. Anaerobe 2015;35:60-65

6. Benedetti G, Campus G, Strohmenger L, Lingström P. Tobacco and dental caries: a systematic review. Acta Odontol Scand 2013;71:363371.

7. Zhang J, Leung KCM, Sardana D, Wong MCM, Lo ECM. Risk predictors of dental root caries: a systematic review. J Dent 2019;10. 
8. El-Ezmerli NF, Gregory RL. Effect of nicotine on biofilm formation of Streptococcus mutans isolates from smoking and non-smoking subjects. J Oral Microbiol 2019;11:1662275.

9. Tanaka S, Shinzawa M, Tokumasu H, Seto K, Tanaka S, Kawakami K. Secondhand smoke and incidence of dental caries in deciduous teeth among children in Japan: population based retrospective cohort study. BMJ 2015;351.

10. Aligne $C A$, Moss ME, Auinger P, Weitzman M. Association of pediatric dental caries with passive smoking. JAMA 2003;289:1258-1264.

11. Shenkin JD, Broffitt B, Levy SM, Warren JJ. The association between environmental tobacco smoke and primary tooth caries. J Public Health Dent 2004;64:184-186.

12. Avsar A, Darka O, Topaloglu B, Bek Y. Association of passive smoking with caries and related salivary biomarkers in young children. Arch Oral Biol 2008;53:969-974.

13. Huang R, Li M, Gregory RL. Nicotine promotes Streptococcus mutans extracellular polysaccharide synthesis, cell aggregation and overall lactate dehydrogenase activity. Arch Oral Biol 2015;60:1083-1090.

14. Balhaddad AA, Melo MAS, Gregory RL. Inhibition of nicotine-induced Streptococcus mutans biofilm formation by salts solutions intended for mouthrinses. Restor Dent Endod 2019:44:e44.

15. Wagenknecht DR, BalHaddad AA, Gregory RL. Effects of Nicotine on Oral Microorganisms, Human Tissues, and the Interactions between Them. Curr Oral Health Rep 2018;5:78-87.

16. Bolortuya G, Ebihara A, Ichinose S, Watanabe S, Anjo T, Kokuzawa C, et al. Initial fibroblast attachment to Erbium:YAG laser-irradiated dentine. Int Endod J 2011;44:1134-1144.

17. DuBois AE, Bennett ZC, Khalid U, Khalid A, Meece RA, Difiore GJ, et al. Nicotine: its stimulating and inhibitory effects on oral microorganisms. Fine Focus 2014;1:63-75.

18. Feyerabend $C$, Higenbottam T, Russell MA. Nicotine concentrations in urine and saliva of smokers and non-smokers. Br Med J Clin Res Ed 1982;284:1002-1004.

19. Hoffmann D, Adams JD. Carcinogenic tobacco-specific N-nitrosamines in snuff and in the saliva of snuff dippers. Cancer Res 1981:41:43054308.

Received April 7, 2020 Accepted July 8, 2020 